\title{
Reflexões metodológicas sobre a historiografia do movimento estudantil ${ }^{1}$
}

\section{SUCUPIRA, Tânia Gorayeb (Fortaleza, Ceará, Brasil) ${ }^{1^{*}}$}

GARCÍA DELGADO, Francisco Javier (Huelva, Andaluzia, Espanha) ${ }^{2 *}$

1 Universidade Federal do Ceará, Faculdade de Educação, Programa de Pós-Graduação em Educação 2Universidade de Huelva, Departamento de História, Instituto de Desenvolvimento Local ORCID ID: http://orcid.org/0000-0001-8087-7651*

ORCID ID: http://orcid.org/0000-0001-8863-4179*

\section{Resumo}

Se a metodologia científica tem a tarefa de melhorar a investigação das questões, a análise dos estudos consagrados no campo das Ciências Sociais mostra lacunas que preenchidas ampliariam a visão do fenômeno. Existem trabalhos que enfatizam a descrição de enredos, atores e eventos, em detrimento de processos estruturados por um longo período, como as nuances da cultura e dos subjetivismos. O trabalho consistiu em sua revisão com base em publicações sobre o movimento estudantil de 1968 na Colômbia, México e Brasil. A hipótese valida o padrão analítico repetido, mas assume que é possível melhorar o registro do fenômeno. A revisão da literatura científica identifica causas, fatores e elementos envolvidos nos processos. Entre os resultados, variáveis comuns que se interconectam em movimentos políticos: perfil do ator, contextos, dinâmica de eventos, aspectos comunicacionais e impactos institucionais.

\section{Palavras-chave}

Movimentos sociais e educação. Crise universitária. Metodologia científica. História da educação.

\section{Child in court: intersection of justice spaces}

\section{and participation rights exercise}

\begin{abstract}
If scientific methodology is tasked with improving the investigation of issues, the analysis of studies enshrined in the Social Sciences field shows gaps that, once filled, would expand the view on the phenomenon. There are studies that emphasize the description of narratives, actors and events, to the detriment of processes structured throughout a long period, such as the nuances of culture and subjectivism. This study consisted of a review based on publications about the student movement in 1968 in Colombia, Mexico and Brazil. The hypothesis validates the repeated analytical standard, but presumes that it is possible to improve the record of the phenomenon. The review of scientific literature identifies causes, factors and elements involved in the processes. Among the results, common variables that interconnect in political movements: actor profile, contexts, event dynamics, communicational aspects and institutional aspects.
\end{abstract}

\section{Keywords}

Social movements and education. University crisis. Scientific methodology. History of education.

\footnotetext{
${ }^{1}$ Artigo apoiado pela Coordenação de Aperfeiçoamento de Pessoal de Nível Superior
} (Capes), mediante Programa de Doutorado Sanduíche no Exterior (Bolsa PDSE). 


\title{
Reflexiones metodológicas sobre la historiografía de movimiento estudiantil
}

\begin{abstract}
Resumen
Si la metodología científica tiene la tarea de mejorar la investigación de las preguntas, el análisis de los estudios consagrados en el campo de las Ciencias Sociales muestra vacíos que llenados ampliarían la visión del fenómeno. Hay trabajos que enfatizan la descripción de tramas, actores y eventos, en detrimento de procesos que se estructuran durante un largo período, como los matices de la cultura y los subjetivismos. El trabajo ha consistido en su revisión basada en publicaciones sobre el movimiento estudiantil de 1968 en Colombia, México y Brasil. La hipótesis valida el patrón analítico que se repite, pero supone que es posible mejorar el registro del fenómeno. La revisión de la literatura científica identifica causas, factores y elementos intervinientes en los procesos. Entre los resultados, variables comunes que se interconectan en los movimientos políticos: perfil del actor, contextos, dinámica de eventos, aspectos comunicacionales e impactos institucionales.
\end{abstract}

Palabras clave

Movimientos sociales y educación. Crisis universitaria. Metodología científica. Historia de la educación.

\section{Introdução}

A educação para a emancipação humana e para o exercício democrático consiste em desejo, utopia e razão para reflexões filosóficas e lutas no campo político, em acordo com Vasconcelos, Fialho e Lopes (2018), mesmo porque pensar o jovem é considerá-lo em sua dimensão naturalmente revolucionária, em que rebeldia e contestação 0 impulsionam para intervir na cultura e atuar na política (VASCONCELOS; FIALHO; LOPES, 2018). No ano de 1968, diante das contradições na dinâmica do desenvolvimento capitalista, um grande movimento envolveu jovens de vários continentes em uma mobilização massiva, ideológica e radical por democracia, autonomia e liberdade (ACEVEDO, 2004; FUENTES, 2008).

Os movimentos estudantis podem ser entendidos como a reação de um grupo frente a mudanças nas estruturas dos sistemas (ACEVEDO, 2015). A expressão sociopolítica de descontentamento envolve um conjunto de interesses, valores e ideias que se convertem em ações coletivas (CRUZ, 2016; DELGADO, 2013), mas as ações comportam dilemas decorrentes do confronto entre os estamentos civil e burocrático. Nesse sentido, a dinâmica de organização e ação coletiva enfrenta uma dialética interna 
(ACEVEDO, 2004) na qual divergências, conflitos e confrontos se apresentam entre indivíduos e grupos (BRAGHINI; CAMESKI, 2015).

Nos anos de 1950, a expansão urbana elevou a demografia das cidades, reduziu postos de trabalho e exigiu investimentos na Educação (MARINI,1970), mas foi na década de 1960, auge da Guerra Fria e avanço do imperialismo na América Latina, que a politização de estudantes na Colômbia (ACEVEDO, 2012, 2015; CRUZ, 2016; HERNÁNDEZ, 2007; SOSA, 2018), no México (ALLIER, 2009; DELGADO, 2013; DONOSO, 2017; FUENTES, 2008; JIMÉNEZ, 2011) e no Brasil (BRAGHINI; CAMESKI, 2015; MORAES FREIRE, 1989; PITTS, 2014) incorporou a militância na perspectiva das lutas de classe para reivindicar a democratização do ensino superior, autonomia e mais recursos financeiros estatais na Educação (MARINI, 1970).

Os estudos consideram os dados econômicos (MARINI, 1970), a conjuntura social (DONOSO, 2017; MORAES, 1989), aspectos da cultura (FUENTES, 2008) e contexto político (PITTS, 2014) para discorrerem acerca das causas e consequências de movimentos estudantis latino-americanos no bojo dos acontecimentos revolucionários globais que tiveram início com o movimento dos estudantes franceses em maio de 1968. A análise preliminar das agitações na Colômbia, México e Brasil destaca elementos que são comuns, como a interferência de agências estadunidenses nas políticas educacionais locais e a repressão das manifestações com violência extremada, mas identifica características específicas ao movimento de cada nação, relacionadas com métodos de protesto, desdobramentos políticos e pautas de reivindicação, bem como ganhos para o alunado e para as instituições de ensino superior.

Diante do exposto, o objetivo principal do trabalho é analisar a metodologia da historiografia de importantes movimentos estudantis. Na Colômbia, destaca-se 0 movimento O Programa Mínimo dos Estudantes, de 1968 a 1971; no México, o movimento estudantil de 1968, que culminou na tragédia de Tlatelolco; e, no Brasil, o movimento estudantil de 1968, auge da ditadura militar, compreendendo elementos contextuais/fatores sociopolíticos e verificando as diferenças/semelhanças de abordagem dos dados entre os estudos distintos. Ademais, identificar possíveis lacunas nos trabalhos dos autores, percebendo a relevância do preenchimento na tarefa de sistematização dos movimentos estudantis. Por fim, discutir uma agenda de trabalho que 
contemple abordagem, procedimentos e interpretação de dados na historiografia dos movimentos estudantis.

\section{Metodologia}

A descrição básica com fins estratégicos espera aprofundar o conhecimento com o intuito de contribuir nos processos de sistematização das pesquisas para fins historiográficos. A seleção dos textos para o estudo foi realizada através de uma busca sistematizada de fontes referentes aos movimentos estudantis de 1968 na Colômbia, México e Brasil. Dos textos selecionados, destacam-se 14 artigos científicos, uma tese de mestrado (JIMÉNEZ, 2011), uma para o grau de licenciado em História (DELGADO, 2013) e um ensaio em forma de relato (FUENTES, 2008). Além de textos em padrão científico, as reflexões e memórias revisitam contextos e expõem os movimentos estudantis latino-americanos. Para a seleção, foram priorizados os documentos que cumpriam prévias condições, a saber:

- Enfoque historiográfico recente, salvo os documentos de contexto (MARINI, 1970; MORAES, 1989) praticamente coetâneos dos acontecimentos;

- Abordagem de fatores e elementos que intervêm no desenvolvimento dos movimentos estudantis;

- Com fontes de informação jornalística (ainda que não exclusivamente);

- Constatáveis (acesso a eles), contrastáveis e contratadas (citadas pela bibliografia sobre o tema);

- O idioma de referência dos países (português e espanhol);

- Equilibrados entre os três países: seis trabalhos para a Colômbia, cinco para o Brasil e cinco para o México, além de um trabalho de referência para a América Latina (MARINI, 1970).

A leitura preliminar destaca fatores, elementos, causas e consequências que são tratados objetivamente como fundamentos históricos. As estruturas são analisadas em seus aspectos comunicacionais, ou seja, dos trabalhos que registram os movimentos estudantis de 1968 na Colômbia, México e Brasil separam-se informações de contextos, conjunturas e dinâmicas de eventos, a exemplo de dados aferíveis e inferíveis nos quais se apoiam as comunicações que caracterizam o fenômeno em cada país. 
É natural observar que há trabalhos que relevam a abordagem quantitativa (MARINI, 1970), enquanto, em outros, a análise se faz por figuras de linguagem, nuances da cultura e subjetivismo (ACEVEDO, 2004; FUENTES, 2008). A fim de organizar a discussão, a sistematização ordena os resultados dos movimentos estudantis em separado, iniciando com a seleção dos documentos quantitativos por país e, na sequência, os qualitativos.

Para facilitar a leitura dos dados objetivos, os quadros informam parte dos resultados de cada autor e respectivos trabalhos, comunicando as informações das categorias mais contempladas naqueles estudos, como expansão das matrículas e da rede de ensino, perfil do alunado e números de manifestações estudantis e de confrontos com forças de repressão. Outros dados objetivos se encontram na exposição que segue cada quadro e são recuperados para amparar a análise e discussão.

O método histórico compreende basicamente duas operações: análise e síntese (BARROS, 2012). Durante a análise, são confrontados os resultados de cada estudo para que se comparem semelhanças e diferenças entre os dados (SOSA, 2018). Os questionamentos iniciais orientam a superação da etapa hermenêutica com base na metodologia comparada (SOSA, 2018). O confronto de documentos dos diferentes movimentos estudantis ressalta ambiente e circunstâncias, em acordo com Sosa (2018, p.37), "[...] con el fin de identificar regularidades y disparidades en los factores contextuales [...] donde se originó el ciclo de movilizaciones estudiantiles", considerando a atenção dada pelos autores.

A análise se volta para a estrutura que comunica os movimentos estudantis de cada país, partindo da hipótese de que haja semelhança de dados do mesmo fenômeno em países distintos, de forma que "[...] las similitudes relevantes de los casos a comparar [...] sirvan como la base orientadora para determinar las diferencias entre cada uno" (KOCKA, 2002, p. 49 apud SOSA, 2018, p. 38). Melhor dizendo: por um lado, o confronto das estruturas evidencia o padrão de dados recorrido e, por outro, os dados que são particulares a cada descrição, expondo as lacunas de comunicação.

A descrição comparativa implica perceber semelhanças e diferenças entre as estruturas dos trabalhos e resulta na síntese, etapa que reúne os elementos concretos e abstratos para formar um todo coerente, restabelecendo um caminho com alternativas metodológicas para os estudos historiográficos. 
Com o propósito de contribuir para futuras discussões acerca do fenômeno, ao final propõe-se uma agenda de trabalho, combinando abordagens e procedimentos que visem a atualizar e ressignificar a prática, contemplando o objeto com completude e aprofundamento.

\section{Resultados}

\subsection{Abordagem quantitativa dos movimentos estudantis}

A análise dos trabalhos relacionados com os movimentos estudantis latino-americanos de 1968 na Colômbia, México e Brasil passa pela investigação das variáveis quantificáveis priorizadas pelos autores, conforme a sistematização que destaca a expansão de matrículas e rede de ensino, investimento estatal na educação, nuances do alunado e do ativismo.

Sobre o contexto educacional na América Latina, o que mobiliza a atenção de Marini (1970) é a contradição percebida quando investigou os números da expansão do sistema nas décadas de 1950 e 1960 frente à alocação dos recursos, conforme demonstram os dados da Quadro 1.

Quadro 1 - Demonstrativo das categorias e respectivos números absolutos e/ou relativos referentes à América Latina

\begin{tabular}{|l|l|}
\hline \multicolumn{1}{|c|}{ Categoria } & \multicolumn{1}{|c|}{ Marini (1970) } \\
\hline Expansão das matrículas & $\begin{array}{l}\text { De 1956 a 1965: 60\% (nível primário); 111\% (nível médio); 92\% } \\
\text { (nível superior). }\end{array}$ \\
\hline $\begin{array}{l}\text { Investimento financeiro estatal } \\
\text { na educação }\end{array}$ & $\begin{array}{l}\text { De 1955 a 1960: nível primário 90\% (insumos e salários) e 10\% } \\
\text { (infraestrutura e capital); nível médio 95\% (insumos e salários) e } \\
5 \% \text { (infraestrutura e capital); nível superior 90\% (insumos e } \\
\text { salários) e 10\% (infraestrutura e capital). }\end{array}$ \\
\hline
\end{tabular}

Fonte: Elaboração própria (2019).

O Quadro 1 apresenta o expressivo crescimento da oferta de educação na América Latina em todos os níveis de ensino, mas a meta assumida pelos governos para investir 4\% do Produto Interno Bruto (PIB) não se concretizou, ressaltando o contraste entre a oferta de vagas e a distribuição dos investimentos (MARINI, 1970).

No mesmo sentido, o Quadro 2 dispõe a expansão do sistema educacional colombiano ao longo das décadas de 1960 e 1970 a partir das categorias que foram priorizadas na análise de diferentes estudiosos. 
Quadro 2 - Demonstrativo das categorias e respectivos números absolutos e/ou relativos referentes à Colômbia por autor analisado

\begin{tabular}{|c|c|c|c|c|}
\hline Categoria & Acevedo (2012) & Acevedo (2015) & Cruz (2016) & Hernández (2007) \\
\hline $\begin{array}{c}\text { Expansão das } \\
\text { matrículas no ensino } \\
\text { superior }\end{array}$ & $\begin{array}{c}\text { Para o caso da } \\
\text { Universidade } \\
\text { Industrial de } \\
\text { Santander (UIS), } \\
\text { passa de } 20, \text { em } \\
1948 \text { para } 5.175 \\
\text { em } 1977 .\end{array}$ & $\begin{array}{c}\text { Até } 1974, \\
\text { 142.000: } 75.500 \\
\text { (públicas) e } \\
66.500 \\
\text { (privadas). }\end{array}$ & & \\
\hline $\begin{array}{l}\text { Expansão da rede de } \\
\text { ensino superior }\end{array}$ & & $\begin{array}{l}\text { Fundação de } 24 \\
\text { instituições } \\
\text { (públicas e } \\
\text { privadas). }\end{array}$ & & $\begin{array}{c}\text { Multiplicação da } \\
\text { oferta da educação } \\
\text { privada de } 1965 \text { a } \\
1975 .\end{array}$ \\
\hline $\begin{array}{l}\text { Dados } \\
\text { socioeconômicos do } \\
\text { alunado }\end{array}$ & & & $\begin{array}{c}\text { Em 1965: 83,3\% } \\
\text { (classe média); } \\
7,6 \% \text { (classe } \\
\text { média-alta); } \\
6,7 \% \text { (classe } \\
\text { alta); } 5,4 \% \\
\text { (classe baixa ou } \\
\text { média-baixa). }\end{array}$ & \\
\hline
\end{tabular}

Fonte: Elaboração própria (2019).

Desde os anos de 1940 que a expansão da educação é destaque na compreensão do contexto educacional colombiano. A Universidade Industrial de Santander (UIS) iniciou atividades em $1^{\circ}$ de março de 1948 de forma tímida, com um grupo de estudantes "[...] que no superó la veintena, entre tres y cinco docentes y un cuerpo administrativo igualmente reducido", destaca Acevedo (2012, p. 378). Contudo, a análise do perfil socioeconômico do alunado da Universidad Nacional, a partir das respostas dos 400 estudantes entrevistados, em 1965, atraiu o interesse de Cruz (2016), atento aos encontros universitários com representantes de 29 universidades e com a assistência de mais de 30.000 estudantes em Bogotá. Inclusive, o autor destacou a tendência esquerdista dos jovens e sua preferência pelos autores marxistas (CRUZ, 2016). Os colombianos que foram para Cuba treinar táticas de guerrilha têm o acordo de Acevedo (2012, p. 384): "[...] De las decenas de jóvenes que se fueran, regresaron siete estudiantes para fundar la guerrilla del ELN, varios de ellos egresados del Colegio de Santander y estudiantes de la UIS". 
Quadro 3 - Demonstrativo das categorias e respectivos números absolutos e/ou relativos referentes ao México por autor analisado

\begin{tabular}{|c|c|c|c|c|c|}
\hline Categoria & $\begin{array}{c}\text { Donoso } \\
(2017)\end{array}$ & $\begin{array}{l}\text { Delgado } \\
\text { (2013) }\end{array}$ & $\begin{array}{l}\text { Hernández } \\
(2007)\end{array}$ & $\begin{array}{c}\text { Allier } \\
(2009)\end{array}$ & $\begin{array}{c}\text { Fuentes } \\
\text { (2008) }\end{array}$ \\
\hline $\begin{array}{l}\text { Expansão das } \\
\text { matrículas no } \\
\text { ensino superior }\end{array}$ & $\begin{array}{c}\text { De } 30 \text { mil em } \\
1950 \text { para } \\
270 \text { mil em } \\
1970 .\end{array}$ & & & & \\
\hline $\begin{array}{l}\text { Investimento } \\
\text { financeiro } \\
\text { estatal na } \\
\text { educação }\end{array}$ & $\begin{array}{c}\text { De } 10 \% \text { em } \\
1950 \text { para } \\
30 \% \text { em } \\
1970 . \\
\end{array}$ & & & & \\
\hline $\begin{array}{l}\text { Número de } \\
\text { estudantes em } \\
\text { manifestações }\end{array}$ & & $\begin{array}{c}\text { Em junho e } \\
\text { julho de } 1968, \\
\text { duas } \\
\text { demonstrações, } \\
\text { cerca de } 10 \text { mil } \\
\text { participantes } \\
\text { em cada. }\end{array}$ & & & $\begin{array}{c}\text { Passeata dos } \\
100 \text { mil } \\
\text { amordaçados. }\end{array}$ \\
\hline $\begin{array}{l}\text { Número de } \\
\text { confrontos com } \\
\text { forças policiais }\end{array}$ & & $\begin{array}{c}\text { Em julho de } \\
\text { 1968: dois } \\
\text { mortos, } \\
\text { centenas de } \\
\text { detidos e } 43 \\
\text { processados. } \\
\text { Em } 2 \text { de } \\
\text { outubro de } \\
\text { 1968: de um } \\
\text { par de dezenas } \\
\text { a várias } \\
\text { centenas, entre } \\
\text { mortos e } \\
\text { feridos, e mais } \\
\text { de mil } \\
\text { encarcerados. }\end{array}$ & $\begin{array}{l}400 \text { mortos, } \\
\text { entre } \\
\text { atendimento a } \\
\text { reclamações } \\
\text { de pessoas } \\
\text { desaparecidas. }\end{array}$ & $\begin{array}{c}\text { Em } 2 \text { de } \\
\text { outubro de } \\
1968, \text { a } \\
\text { discrepância } \\
\text { das fontes: } 30 \\
\text { mortos, } 53 \\
\text { feridos graves e } \\
\text { mais de } 1.500 \\
\text { presos (diário } \\
\text { Excelsior); } 150 \\
\text { mortos (CNH); } \\
150 \text { a 200 } \\
\text { mortos (arquivo } \\
\text { da Universidade } \\
\text { George } \\
\text { Washington); } \\
350 \text { mortos } \\
\text { (arquivo da } \\
\text { Embaixada dos } \\
\text { Estados Unidos } \\
\text { no México). }\end{array}$ & $\begin{array}{c}\text { Em } 3 \text { de } \\
\text { outubro de } \\
\text { 1968: a } \\
\text { proibição por } \\
\text { Díaz Ordaz } \\
\text { dos } 500 \\
\text { cortejos } \\
\text { fúnebres na } \\
\text { Cidade do } \\
\text { México. }\end{array}$ \\
\hline
\end{tabular}

Fonte: Elaboração própria (2019).

No México, o Quadro 3 mostra o reflexo dos investimentos na expansão das matrículas em apenas duas décadas, em contraste com a média da escolaridade: menos de quatro anos, observa Donoso (2017). Em Delgado (2013, p. 58) - “[...] Para 1968 había nueve países latinoamericanos sometidos a los Estados Unidos, para 1973 se sumarían Chile y Uruguay [...]' - importou quantificar o avanço do imperialismo e da resistência do Partido Comunista Mexicano (PCM), com dois a três mil filiados. Acerca dos números do Consejo Nacional de Huelga $(\mathrm{CNH})$, iniciou com 222 delegados, representando 74 escolas, mas foram reduzidos a 148, dois por escola, e "[...] los jóvenes comunistas 
sumaban cuarenta delegados, es decir, entre el 17 y 25 por ciento [...]' (DELGADO, 2013, p. 81). Fuentes (2008, p. 148) corrobora Hernández (2007) acerca do protesto silencioso contra a desigualdade: "[...] sessenta pessoas têm mais dinheiro que 60 milhões de cidadãos". A dimensão historiográfica da matança de Tlatelolco é destaque para Jiménez (2011, p. 57): "[...] 55 reimpressões da primeira edição de La noche de Tlatelolco de Poniatowska e 10 da segunda edição, de 1998, assim como os 612 testemunhos que dão suporte às obras do historiador".

Quadro 4 - Brasil: demonstrativo das categorias e respectivos números absolutos e/ou relativos referentes ao Brasil por autor analisado

\begin{tabular}{|c|c|c|c|}
\hline Categoria & Moraes (1998) & Pitts (2014) & Reis Filho (1998) \\
\hline $\begin{array}{l}\text { Expansão das matrículas } \\
\text { no ensino superior }\end{array}$ & & $\begin{array}{c}\text { Em 1945: } 27.253 \text {, para } \\
\text { 1960: 93.202 e para } \\
\text { 1968: } 278.295 \\
\text { (LANGLAND, 2013, p. } \\
\text { 72). }\end{array}$ & $\begin{array}{l}\text { Em torno de } 200 \text { mil } \\
\text { jovens, cerca de } 0,5 \% \\
\text { da população. }\end{array}$ \\
\hline $\begin{array}{l}\text { Número de estudantes } \\
\text { em manifestações }\end{array}$ & $\begin{array}{c}\text { Em junho de } 1968, \\
\text { passeata com } 100 \text { mil. }\end{array}$ & $\begin{array}{c}\text { Em junho de } 1968, \\
\text { passeata com } 100 \text { mil. } \\
\text { Em } 29 \text { de agosto de } \\
\text { 1968: } 300 \text { estudantes } \\
\text { marchando através do } \\
\text { campus com } \\
\text { metralhadoras } \\
\text { apontadas para suas } \\
\text { cabeças. }\end{array}$ & \\
\hline $\begin{array}{l}\text { Número de confrontos } \\
\text { com forças policiais }\end{array}$ & & $\begin{array}{l}\text { Em } 29 \text { de agosto de } \\
\text { 1968: } 200 \text { policiais } \\
\text { militares invadiram a } \\
\text { Universidade de } \\
\text { Brasília (UNB) para } \\
\text { prender Honestino } \\
\text { Guimarães e outros } \\
\text { quatro militantes. } \\
\text { Em } 2 \text { de outubro: } \\
\text { presos centenas de } \\
\text { militantes estudantis. }\end{array}$ & \\
\hline
\end{tabular}

Fonte: Elaboração própria (2019).

Soares e Petarnella (2009, p. 340) repercutem Jean Pronteau: “[...] o fenômeno da quantidade é de importância primordial", com o acordo de Henri Lefebvre (1968, p. 15-18 apud SOARES; PETARNELLA, 2009, p. 340) - “[...] Éramos 50.000 quando eu era estudante, são agora mais de 600.000 e há 1.200 .000 alunos nos cursos finais que marcham na mesma direção [...]" - e dados postos por Carlos Fuentes (SOARES; PETERNELLA, 2009, p. 346): 
[...] Em 1945, havia cerca de 120 mil estudantes nas universidades francesas; hoje a soma se eleva a mais de meio milhão, e só na Sorbonne há 160 mil. Não cabemos nas salas [...]. Mais de 30 mil estudantes querem utilizar a biblioteca, mas só há capacidade para quinhentos leitores.

A ocupação de Nanterre por 142 estudantes, em 22 de março, indica 0 prenúncio do simbólico "Maio de 1968", mas não para Moraes (1989, p. 138): "[...] evidente que a mobilização estudantil de massa desencadeou-se primeiro no Brasil - e não na França". O Correio da Manhã de 23 de março de 1968 informou sobre o movimento estudantil que interditara a Faculdade de Filosofia da Universidade de São Paulo (USP), depois que "excedentes" dos concursos invadiram a universidade para exigir mais vagas, inclusive o Quadro 4 apresenta a expansão do sistema.

Os estudantes confrontavam os políticos diretamente, como no episódio que envolveu Roberto Costa de Abreu Sodré, governante de São Paulo. Em 1ํ de maio de 1968, ele tentou discursar na Praça da Sé para 10 mil trabalhadores e estudantes, mas foi apedrejado e xingado de "Assassino!" e "Interventor!". Desde a morte do estudante Edson Luís pela Polícia Militar, em 28 de março, houve várias passeatas. Em 29 de agosto, na UnB, houve viatura virada e incendiada, policiais chutando portas e destruindo laboratórios com cassetetes, metralhadoras, rifles e gás lacrimogêneo. Do Congresso Nacional, "[...] ao menos vinte deputados e três senadores de ambos os partidos $^{3}$ seguiram para o campus [...]" (PITTS, 2014, p. 50). No saldo da repressão, um estudante com bala na cabeça, outro no joelho e alguns ossos fraturados. Lida na tribuna, a carta assinada por 175 mães e esposas de pelo menos 30 deputados e senadores repudiou a violência do Estado. É fato que $80 \%$ dos deputados haviam frequentado a universidade, mas havia pouco em comum entre os universitários e os políticos (PITTS, 2014), e os "estudantes democráticos" recusavam-se a ser representados por uma "minoria extremista" (BRAGHINI; CAMESKI, 2015).

2 O Movimento de Maio de 1968 tornou-se ícone de uma época por sua representatividade, agregando jovens de várias partes do mundo e por sua característica revolucionária de valores e costumes, com inúmeras expressões artísticas, políticas, filosóficas e culturais.

3 Em 1966, os partidos extintos no ano anterior foram obrigados a se reorganizar em dois grupos: Aliança Renovadora Nacional (Arena), alinhado com o regime militar, e Movimento Democrático Brasileiro (MDB), a oposição consentida. 


\subsection{Abordagem qualitativa dos movimentos estudantis}

A estratégia de cooperação mútua contra a ameaça comunista no Ocidente ganhou novos contornos ideológicos desde a Revolução Cubana. Na década de 1960, a "Aliança para o Progresso" reformou os sistemas educacionais dos países. Os eixos do programa estruturaram a política de auxílio financeiro e apoio técnico para a modernização educacional nos sistemas, em acordo com o modelo cultural norte-americano. O documento de Rudolph Atcon aparece em Acevedo (2012, 2015), Cruz (2016) e Sosa (2018). Além de reduzir a educação superior à formação técnica e profissionalizante, o plano defendia uma lógica empresarial de privatização da educação (HERNÁNDEZ, 2007).

Acevedo (2015) analisa as alterações filosóficas, estruturais, curriculares, de gestão administrativa, formação docente e disciplinar no sistema educacional colombiano e Acevedo (2012) revisita a história da UIS desde a criação, voltada para o ensino tecnicista, até os conflitos, no período de reformas. Além dos marxistas de Acevedo (2004) e Cruz (2016), dos anti-imperialistas de Acevedo (2015) e dos jovens líderes empresariais de Sosa (2018), estudos se referem aos anarquistas e Comandos Camilistas ${ }^{4}$, de acordo com Cruz (2016). Os "[...] actos para subvertir el orden o intentos revolucionarios" (SOSA, 2018, p. 53) compunham a tese de conspiração comum aos governos latino-americanos desse período, que viam nos movimentos estudantis a ameaça comunista e o perigo do inimigo interno, conforme Acevedo (2015), Cruz (2016) e Sosa (2018). A cultura estudantil está em Acevedo (2004, p. 164): "[...] Ser joven ya no era uma fase preparatoria para la vida adulta, sino la fase culminante del pleno desarrollo humano [...], ningún movimento revolucionario en la historia haya tenido más personas que leían y escribían libros". A revolução da cultura, do pensamento e do comportamento é compartilhada por toda uma geração, com pensamentos humanitários, ideais transformadores e formas de consumo semelhantes, desde várias partes do mundo:

[...] solo hay que pasar una rápida mirada al joven rebelde mexicano de 1968 para entender que no se distanciaba casi nada del colombiano, norteamericano $o$ europeo [...]. Ésta fue una generación que no solo respondió a las identidades de la izquierda, sino de lo psicodélico, lo hippie, la marihuana, la televisión. (ACEVEDO, 2004, p. 164; 173).

4 "Uno de estos colectivos del campo del socialismo revolucionario en Colombia" (ACEVEDO, 2019, p. 128).

Educação \& Formação, Fortaleza, v. 5, n. 14, p. 216-239, maio/ago. 2020

DOI: https://doi.org/10.25053/redufor.v5i14mai/ago.2750

http://seer.uece.br/redufor 
Marini (1970) avalia o êxito em função da aliança com camponeses, classe média e subproletariado urbano, mas Acevedo (2004) e Hernández (2007) destacam as assembleias universitárias: debates, confrontos, dissensos e enfrentamentos, um autêntico "espectáculo". Na greve dos estudantes da UIS, o protesto contra o corte de investimentos, em Cruz (2016) e Hernández (2007), insatisfação em relação aos "Cuerpos de Paz", as missões de estadunidenses para investigar riquezas naturais e saberes dos povos originários. A Fundação Ford foi expulsa do Departamento de Sociologia da Universidad Nacional (ACEVEDO, 2015) e Corpos de Paz da Universidad del Valle foram acusados de serem espiões da Central Intelligence Agency (CIA). Na Universidad Nacional, os estudantes entraram em greve pelo direito de repetir um ano (HERNÁNDEZ, 2007).

Sobre 1968 no México, Jiménez (2011) destaca a importância política da 19a edição dos Jogos Olímpicos e a agenda da agitação aparece em Delgado (2013, p. 58): "[...] el tres de febrero de 1968 se inició en Dolores Hidalgo La Marcha por la Ruta de la Libertad', com a Central Nacional dos Estudantes Democráticos (CNED) e a Juventude Comunista, mas o exército dissolveu a marcha e prendeu os líderes três dias depois. No dia 10 de março, o PCM denunciou a repressão do governo e foi acusado de subverter a ordem, em diários da Cidade do México; em 7 de maio, houve a primeira reunião entre 0 presidente Díaz Ordaz e o PCM, visto como "[...] un grupo conspirador [...]" (DELGADO, 2013, p. 61). Os comunistas defendiam democracia, fim da repressão e mais participação política. Os confrontos, desde 22 de julho, entre estudantes das Vocacionales 2 e 5 do Instituto Politécnico Nacional e da escola particular Isaac Ochoterena (preparatória para a Universidad Nacional Autónoma del México - UNAM), foram reprimidos com a força. $O$ autoritarismo do presidente Díaz Ordaz está na raiz dos protestos estudantis de 1968 para Allier (2009), Delgado (2013), Donoso (2017), Fuentes (2008) e Jiménez (2011). Jiménez (2011) endossa o protagonismo dos comunistas e narrativas apontam que o Partido Comunista da União Soviética (PCUS) "[...] apoyó el PCM con alrededor de 25 mil dólares" (DELGADO, 2013, p. 65). Allier (2009, p. 293) cita a "teoría de la conjura", que fundamentou a perseguição aos estudantes. As passeatas de 26 de julho, contra a violência do Corpo de Granadeiros e para enaltecer a Revolução Cubana, são destacadas por Delgado (2013) e Jiménez (2011), incluindo a repressão. Graças ao apoio da imprensa, a opinião pública acolheu a tese de ameaça comunista, mas a narrativa de 
Alma Silvia Díaz Escoto se refere a "[...] diferentes formaciones políticas [...]" em Delgado (2013, p. 79), inclusive estudantes direitistas, "[...] los grupos anticomunistas como el MURO (Movimiento Universitario de Renovadora Orientación) e el PUM' (DELGADO, 2013, p. 87), que concordavam com a pauta da autonomia, mas acusavam comunistas de conspiradores. Fatos de 30 de julho estão em Delgado (2013) e Donoso (2017), quando militares fizeram disparos com grosso calibre contra uma instituição educacional e o reitor da UNAM içou a bandeira da Cidade Universitária a meio mastro, encabeçando a marcha estudantil de $1^{\circ}$ de agosto. Em 2 de agosto, o Daily News destacou a participação de Fidel Castro nos distúrbios do México, conforme Allier (2009) e Delgado (2013), citando "forças ocultas", ou a CIA, que se aproveitava da rebeldia estudantil para desestabilizar a democracia. O massacre de Tlatelolco, em 2 de outubro, ocupa o terceiro capítulo de Fuentes (2008). O autor narra a tragédia recorrendo às memórias de uma fotógrafa, desde a "[...] presença das tropas policiais ao chacoalhar contra a porta da Preparatória para a tomada da Cidade Universitária pelo exército" (FUENTES, 2008, p. 145), o que ela viu, sentiu e acreditou. Marini (1970) avalia que a contenção sistemática e, por vezes, brutal não permitiu aos estudantes consolidar junto com os trabalhadores um movimento de massa capaz de resistir à repressão do governo. Donoso (2017) reuniu documentos de fontes primárias: discursos, manifestos, impressos e volantes, além de onze entrevistas semiestruturadas com historiadores, entre os quais Acevedo (2011 e 2012) e Allier (2009).

A ação direta estadunidense nos assuntos educacionais do Brasil aparece no acordo da United States Agency for International Development (Usaid) ${ }^{5}$ feito pelos militares depois do Golpe de 1964. Fator de grandes mobilizações estudantis, restringiu investimentos públicos e estimulou o setor privado na educação superior, em acordo com tese de Rudolph Atcon: "[...] La Universidad es una gran empresa, y no una oficina pública [...]' (MARINI, 1970, p. 115). A organização política dos trabalhadores foi proibida, mas os estudantes ainda dispunham de uma organização independente, a "[...] Unión Nacional de Estudiantes (UNEB)" (MARINI, 1970, p. 119), mas até a direita estudantil se recolheu: "[...] só restou a ação mais radical, agrupada no Comando de Caça aos Comunistas (CCC) e grupos afins" (REIS FILHO, 1998, p. 30).

5 United States Agency for International Development (Usaid), escritório norte-americano surgido em 1961 a partir do Decreto de Assistência Externa do então presidente John F. Kennedy. A agência estava encarregada de distribuir ajuda externa de caráter civil e com fins estratégicos.

Educação \& Formação, Fortaleza, v. 5, n. 14, p. 216-239, maio/ago. 2020

DOI: https://doi.org/10.25053/redufor.v5i14mai/ago.2750

http://seer.uece.br/redufor 
No período imediato à instauração da ditadura, o movimento estudantil foi frágil e molecular: vaias, protestos e pequenas passeatas reprimidas com tiros e prisões; o ativismo ficou com os meios de comunicação: "[...] Jornais ainda, mas já, e sobretudo, a televisão [...] informando, sensibilizando e despertando" (REIS FILHO, 1998, p. 31). Na clandestinidade, os estudantes gestavam as vanguardas revolucionárias e a luta armada. Vladimir Palmeira, na posição de dirigente, defendia a queda do regime militar e um governo alinhado com o regime cubano, segundo Moraes (1989), que cita, entre as primeiras mobilizações massivas de 1968, a ocupação da Faculdade de Filosofia da Universidade de São Paulo, em 22 de março, e a crise do restaurante que atendia a estudantes carentes no Rio de Janeiro.

Pitts (2014) recorda que os protestos se dirigiam às demandas acadêmicas: mais vagas nas universidades e gestão mais democrática, mas a luta foi radicalizada em 28 de março, quando o secundarista Edson Luís de Lima Souto foi assassinado nos protestos do "Calabouço" (MORAES FREIRE, 2008; MORAES, 1989; PITTS, 2014; REIS FILHO, 1998). Revoltada, a sociedade foi para as ruas em várias cidades contra a violência da repressão. A Passeata dos Cem Mil é destaque para Moraes (1989), Pitts (2014) e Reis Filho (1998), que inclui a exaltação da Revolução Cubana no XX Congresso Nacional da União Brasileira dos Estudantes Secundários (Ubes) e a ousadia dos estudantes que elegeram Che Guevara como presidente de honra post mortem.

Dessa vanguarda saíram os revolucionários para o combate frontal com a ditadura (MORAES, 1989). Em Reis Filho (1998, p. 25), 1968 é um palco: "[...] Observemos o cenário, enquanto os atores se preparam para entrar em cena [...]": de um lado, os militares armados com metralhadoras e decretos para impor à força o regime, fechando instituições e reprimindo com atos e violência qualquer oposição; e, do outro, o apoio da igreja católica, dos ruralistas e dos empresários, com metáforas, metonímias e simbolismos: "[...] Ali se reuniram a espada, a cruz, a propriedade e o dinheiro [...]" (REIS FILHO, 1998, p. 26). O estudante revolucionário era visto como "pequeno-burguês", mas Reis Filho (1998) cita alguns atores "coadjuvantes", os intelectuais, jornalistas, artistas e religiosos, bem como os protestos em shows e festivais.

Coadjuvantes secundários, os trabalhadores tiveram sindicatos fechados, seus líderes exilados e o direito de greve proibido, restando o arrocho salarial, a perda da estabilidade e as portas do palácio fechadas. Abreu Sodré, o governador da ditadura, 
fracassou no discurso da Praça da Sé em 1ํ de maio de 1968, expulso pelos atores mais importantes e decisivos (MORAES, 1989; REIS FILHO, 1998), os estudantes. Neutra ou a favor do regime, a juventude considerada de "direita" aparece em Moraes (1989) e é objeto da investigação de Braghini e Cameski (2015). A pesquisa, na seção "Opiniões do mês" da Revista de Editora do Brasil S/A, nas notícias de diários, em leis e atas de comissões de ensino, ressalta a dicotomia "direitista/esquerdista" e o confronto cultural entre o bem (bons estudantes) e o mal (subversivos).

\section{Discussão}

A historiografia é a arte de descrever fatos e façanhas dos homens no tempo. $\mathrm{O}$ historiógrafo Álvaro Acevedo é referência para o estudo dos movimentos estudantis na América Latina, mas ele adverte: "[...] el historiador ve solo lo que quiere ver [...]" (ACEVEDO, 2004, p. 163) e opta por compreender as mobilizações estudantis através de aspectos culturais da sociedade global de dois tempos: em 1968 e quatro décadas depois. A busca por números daqueles contextos é irrelevante quando há um universo de dados subjetivos, entre os políticos, "[...] Tal vez 1968 pueda marcar el primer quiebre binario de la Guerra Fría [...], una Internacional de estudiantes, avalada por um 'conspirativo' para socavar los cimientos del Occidente capitalista [...]' (ACEVEDO, 2004, p. 163); as produções culturais que revolucionaram o campo das artes e "[...] trascienden las fronteras nacionales para inscribirse en una experiencia global [...]' (ACEVEDO, 2004, p. 163).

Acevedo (2012) conta com o acervo institucional para discorrer sobre a história da UIS, entre 1953 e 1977, desde a concepção até os movimentos dos estudantes, passando pela dinâmica dos acontecimentos durante a modernização e os conflitos que cercam a mobilização estudantil. $O$ arquivo com relatórios, documentos oficiais e publicações de periódicos oferece suporte para o registro histórico da instituição, mas, corroborando o autor, entre "[...] los vestigios de la organización universitaria" (ACEVEDO, 2012, p. 373), existe uma lacuna de documentos e informações que poderiam dar conta de representar a dimensão da experiência sociopolítica e dos meandros da cultura universitária e protagonismo estudantil.

Acevedo (2015) revisa a bibliografia para investigar o contexto político, econômico e social da Colômbia durante a implantação do Plano Atcon. A passagem rápida pelos 
acontecimentos de 1968 justifica a brevidade com que analisa a representação da identidade cultural daquela juventude, seus modos de vida e hábitos de consumo, diante da magnitude da experiência revolucionária própria dos anos que movimentaram a geração: cultural, artística e politicamente. E resta, inclusive, curiosidade acerca dos subjetivismos que envolvem os estudantes que se opuseram ou se omitiram aos movimentos de protesto e como eles se manifestaram na correlação de forças.

Edwin Cruz se dedica ao estudo da teoria e práticas políticas. Cruz (2016) analisa o percurso de formação da juventude colombiana de ideologia esquerdista, a insatisfação dos estudantes, a organização das assembleias e as ações coletivas contra o Plano Básico de reforma universitária. Os fatores dos protestos estudantis de 1968 estão ordenados, seguidos do texto que esmiúça a mobilização contra as interferências estrangeiras e o avanço da privatização da educação superior, incluindo as consignas dos discentes durante as manifestações. A análise do fenômeno estudantil na década de 1960 passa rápido pelo revolucionário 1968, "[...] fueron las organizaciones de izquierda, impregnadas de la transformación global que en esos años se presentaba [...]' (CRUZ, 2016, p. 229). Inquieta saber se/como a juventude esquerdista foi impactada, desde a atitude política até a identidade e as linguagens.

Isabel Hernández se dedicou ao estudo de um dos mais expressivos movimentos estudantis na Colômbia e orienta ser necessário compreender o fenômeno tendo em conta o contexto em que se deram "[...] las circunstancias políticas, económicas y sociales de las décadas de los años sesenta y setenta [...]' (HERNÁNDEZ, 2007, p. 31). Dada a relevância que concerne ao estudo dos antecedentes do Movimento Programa Mínimo dos Estudantes Colombianos, são breves e superficiais as representações que abordam 0 revolucionário 1968, “[...] los vientos de la primavera francesa de mayo de 1968 también se sintieron en las universidades colombianas [...]. Más cercano, el Movimiento de 1968 en Tlatelolco - México [...]" (HERNÁNDEZ, 2007, p. 35). Após anos sob a influência dos padrões europeu e norte-americano, a universidade colombiana busca preencher o acervo sistematizado com os traços da cultura acadêmica que denotem sua identidade própria.

Yeison Sosa em seu trabalho faz uma leitura comparada dos movimentos estudantis naquela universidade, entre duas épocas: 1968-1971 e 2007-2011. A investigação das condições para o surgimento dos protestos antecipa que, além das reformas educativas e do regime político, os aspectos culturais também contribuíram para 
tornar crítica a situação entre os estudantes e o governo. Sob essa óptica, o pesquisador observa o privilégio dado a estudos específicos, "[...] como los años 70, dejando de lado otras temporalidades [...]' (SOSA, 2018, p. 36), não se aprofundando nos detalhes dos eventos de 1968. Foi nesse ano que os estudantes da Universidad del Valle se mobilizaram para expulsar da instituição os membros dos "Cuerpos de Paz", abrindo mão das aulas de inglês, orientações e assessoramentos. Escava nos escrutínios do tempo a matéria-prima do seu trabalho e, por certo, conteúdos de assembleias, reuniões e mobilizações precedem ao afastamento compulsório de estrangeiros de uma instituição de ensino superior. A reprodução do comunicado da Federação de Estudantes da Universidad del Valle, em Sosa (2018), repudia o Plano Básico de reforma do ensino, mas não se aprofunda na problemática que envolveu a interação da comunidade com os jovens dos Corpos de Paz.

O movimento mexicano de 1968 é tema de Andrés Donoso, da Universidad de Playa Ancha, no Chile. Fontes secundárias e entrevistas com especialistas esperam transcender o massacre de 2 de outubro e ampliar o horizonte espacial e temporal de análise. $O$ trabalho atenta para interações sociais, descrevendo a ação das brigadas: "[...] grupos de cinco o seis estudiantes que se desparramaban por las principales ciudades del país para informar sobre los pormenores del movimiento [...]' (DONOSO, 2017, p. 144); tal como sucedeu no Chile, em 2011, os mexicanos foram engenhosos para obter a adesão da população e "[...] el movimiento mexicano de 1968 logró ser, para muchos de sus participantes, una verdadera fiesta [...]' (DONOSO, 2017, p. 144). O esforço de se aprofundar nas nuances da cultura fomentada nas relações entre os indivíduos e grupos e na expressão de subjetividades pode enriquecer a historiografia dos movimentos estudantis - pois importa saber acerca das crenças -, a natureza dos diálogos e as formas das expressões e linguagens das artes nas interações.

Kevyn Simón Delgado pesquisa a história do Partido Comunista Mexicano. As páginas com a historiografia dos movimentos estudantis de 1968 comportam documentos de narrativas, notícias e arquivos oficiais, descrevendo os fatos anuais, desde "La Marcha por la Ruta de la Liberdad", com os estudantes democráticos e a juventude comunista, em 3 de fevereiro de 1968, até a "[...] campaña 68: un millón al PCM [...]' (DELGADO, 2013, p. 122), iniciada em 11 de dezembro, para arrecadar os fundos para o partido. Contudo, a fonte historiográfica crescerá com o aporte de uma 
descrição de cunho etnográfico, de onde se depreendam os subjetivismos das militâncias de esquerda e de direita, os saberes das experiências de vida e produtos da cultura consumidos pelos estudantes: livros, músicas, artes e espaços culturais.

$\mathrm{O}$ artigo de Eugenia Allier traz resultados de dois projetos desenvolvidos com sua equipe: um envolvendo a investigação das memórias da violência política no México e Uruguai e outro aprofundando a discussão da memória política no México, aqui analisado. O texto transita entre a memória deixada pelos fatos sociopolíticos de 1968 a 2007. Sobre os movimentos de 1968, a pesquisadora se dedica à revisão bibliográfica e consulta de documentos, inclusive diversas fontes, entre arquivos e relatórios que apontam para as contradições (DELGADO, 2013; FUENTES, 2008; JIMÉNEZ, 2011) quanto ao número de mortos no massacre de 2 de outubro. Ante o mistério que envolve o montante exato de jovens que caíram tragicamente sem vida, desaparecidos ou presos, esse esforço de investigação em Allier (2009) se sobressai, não obstante a opção pelo breve discurso, à borda dos fatos.

Desde 2011, Héctor Jiménez, em uma extensa tese em Historiografia do México pela Universidad Autónoma Metropolitana Azcapotzalco, realiza aprofundada revisita a um conjunto de obras, arquivos e documentos e faz uma crítica historiográfica dos acontecimentos de 1968 no país. Diante do grande volume de trabalhos já publicados, Jiménez (2011, p. 140) se refere aos "[...] problemas para construir una historia sobre el movimiento estudiantil, que trasciendiera la visión anecdótica y testimonial de dicha experiencia [...]'. Decerto que o historiógrafo privilegiou a perspectiva da juventude comunista, vislumbrando amplamente os atores e o roteiro daquele enredo. Se fosse possível algo mais, seria o legado artístico: obras, expressões e linguagens. Melhor perguntando, como a onda que revolucionou mundialmente a cultura impactou a produção intelectual e artística mexicana reprimida, violentada e censurada?

Fuentes (2008) dedica 11 páginas para os horrores do confronto fatal entre estudantes e forças policiais. Sentidos e emoções da tragédia de Tlatelolco aparecem nas memórias e testemunhos do massacre de dezenas ou centenas de jovens na Praça das Três Culturas. Narra com os sentidos, registrando o universo subjetivo das vivências de Laura: a experiência, a expectativa, a saudade, a admiração e a dor máxima da perda do jovem Santiago III. Embora pareça pequeno, literalmente, o texto pulsa imenso, completo e inesquecível em significações. 
Ruy Mauro Marini estudou variáveis sociais, econômicas e políticas para formular a Teoria da Dependência, em que o atraso dos países se explica pela dependência do capitalismo de países centrais, condição agrário-exportadora e posição na divisão internacional do trabalho. Sua análise dos movimentos estudantis latino-americanos de 1968 se concentra na objetividade do fenômeno. De uma visão estatística do contexto ele chega à raiz dos protestos, uma contradição: a quantidade de recursos financeiros insuficientes para atender à demanda crescente de matrículas: "[...] después del golpe militar de 1964, el gobierno [...] no solo restringió el gasto educativo público [...]' (MARINI, 1970, p. 116). O autor opta por não contemplar subjetivismos.

Silene de Moraes Freire é socióloga e sua análise teórico-interpretativa da história do movimento de estudantes no Brasil antecipa: "[...] Não almejamos oferecer [...] uma interpretação da 'singularidade' histórica do movimento estudantil brasileiro" (MORAES FREIRE, 2008, p. 133). A pesquisa traz as campanhas no restaurante Calabouço e a ação articulada junto com a União Nacional dos Estudantes (UNE), "[...] um pequeno grupo organizou uma dramatização das queixas em frente ao restaurante" (MORAES FREIRE, 2008, p. 136).

$O$ registro de fenômenos sociais se enriquece quando atenta para detalhes: linguagens da revolta popular e formas de arte que expressam indignação e afirmam reivindicações. Com tradução de Alexandre Fortes, Pitts (2014) visita bibliografias, hemerotecas, arquivos públicos, Diário da Câmara dos Deputados, além de um documentário (filme) para compreender como a revolução democrática em 1964 assumiu a face ditatorial, radicalizando a repressão em 1968. Nesse sentido, o professor assevera ser necessário buscar "[...] no comportamento e [...] palavras da classe política" (PITTS, 2014, p. 41) resposta para os questionamentos.

João Quartim de Moraes contribui com o trabalho baseado na revisão bibliográfica do golpe de 1964 (MORAES, 1989). O autor se concentrou na vanguarda revolucionária que abraçou a luta armada em 1968, na ocupação da Faculdade de Filosofia da Universidade de São Paulo (USP) e nas grandes passeatas em protesto contra o assassinato do estudante Edson Luís de Lima Souto. Desde a década de 1970, a corrente historiográfica denominada Nova História valoriza a ampliação das fontes (BURKE, 2003). As memórias e narrativas de protagonistas e testemunhas dos 
acontecimentos no tempo em que estes se passam são valiosas fontes de documentos históricos e valores culturais que enriquecem as pesquisas.

Reis Filho aponta para questões que permanecem em aberto em torno dos nexos e ligações entre a ruptura institucional de 31 de março 1964 e a radicalização, em 1968, independentemente do aspecto de endurecimento do regime como imposição da força repressora. O olhar científico sobre o fenômeno não pode prescindir de explorar os subterrâneos dos fatos e acontecimentos que problematizam o universo subjetivo e lacunas que surgem entre questionamentos e contraditórios. Quando preenchidas as lacunas, resultam novas perspectivas do objeto.

Katya Zuquim Braghini e Andrezza Silva Cameski são educadoras e trazem o ativismo do grupo que "[...] aprovava a condução política do governo militar, após o golpe de estado em 1964 e fez oposição à ação de seus colegas, pares etários, considerados 'comunistas' [...]" (BRAGHINI; CAMESKI 2015, p. 946). As contradições sociais no fenômeno foram analisadas através do conteúdo de uma publicação parceira do regime instituído. Os textos publicados partiam de diários do país, leis e atas de comissões de ensino e as professoras buscavam ali os estereótipos no senso comum e a produção da cultura que representa o estudante de "bem" e seu par etário subversivo, o do "mal". Afora o fato de ser possível acessar os documentos diretamente, a pesquisa à fonte original torna possível diversificar, aprofundar, ratificar ou mesmo refutar a interpretação dada por outrem a representações culturais e fatos sócio-históricos.

\section{Considerações finais}

A revisão dos trabalhos atentou para fatores, causas e consequências presentes entre os resultados, destacando aspectos que recorrem e prevalecem nas análises dos estudiosos, além de lacunas de hipóteses e problematizações. O esforço crítico levou à reflexão de uma agenda de trabalho que intenta auxiliar a investigação do fenômeno.

A respeito dos números dos contextos em que se passam eventos sócio-históricos, concorda-se com Ramos e Monsma (2012) quando alertam para o equívoco de reduzir a abordagem quantitativa à mera técnica de quantificação, porque há um universo de significações nem sempre evidentes. Orienta-se o uso de métodos estatísticos no apoio para a discussão acerca de causalidades, "[...] estruturas de significação embutidas em 
diversas representações sociais e nas respostas de entrevistados" (RAMOS; MONSMA, 2012, p. 15).

Soberana na investigação nas áreas de Ciências Humanas e Sociais, a pesquisa qualitativa não deve se limitar à simples discussão descritiva dos fatos, acontecimentos e sujeitos que integram os fenômenos históricos. Chizzotti (2003) atenta para o cunho pedagógico das pesquisas e sugere ao pesquisador o exercício da criatividade, 0 adensamento de hipóteses e a flexibilidade no olhar, buscando no tempo as problemáticas que se relacionam com os sujeitos e as classes, como as questões de gênero, etnia, raça, sexualidade, estético-artísticas e ético-políticas.

Mediante as intenções da pesquisa, as vozes e os silêncios dos atores possuem igual importância no momento de entender os sentidos, significados e valores dados nos contextos. A aproximação densa e profunda com pessoas, fatos e locais que constituem o objeto, no sentido de "[...] extrair desse convívio os significados visíveis e latentes que somente são perceptíveis a uma atenção sensível [...]", segundo Chizzotti (2003, p. 221), é possível pela partilha e quando há forte envolvimento.

A problematização dos movimentos estudantis transcende o conteúdo reformista e anti-imperialista para abarcar, pelo menos, mais três dimensões do ator social, conforme Acevedo e Samacá (2011, p. 114): "[...] la generacional, la adscripición socioeconómica a los sectores medios y la condición de jóvenes criadores de códigos y referencias culturales". Isto é possível a partir do diálogo entremeado com a história socioeconômica, a história dos movimentos sociais e a história cultural e acrescentando as experiências acadêmicas e não acadêmicas de diferentes gerações de estudantes e ideologias (esquerda, direita, anarquista, nilista), vivências políticas e consumos culturais dentro e fora das academias, além das interações sociais nos espaços de organização política, cultural e de lazer.

A renovação das investigações dos movimentos estudantis passa pela compreensão das diferentes linguagens que os sujeitos utilizam para comunicar, difundir e informar as práticas e vivências. Nesse sentido, as tecnologias digitais representam fonte de coleta considerável, entre sites, redes sociais e diferentes mídias de interação e disseminação de informações. O estudo pode alargar o espaço subjetivo e incluir as representações de docentes e técnicos administrativos, afora as lutas políticas dos demais colaboradores e terceirizados das instituições. 


\section{Referências}

ACEVEDO, Á. Educación, reformas y movimientos universitarios en Colombia: apuestas y frustraciones por un proyecto modernizador en el siglo XX. Revista de Estudios Sociales, Bogotá, n. 53, p. 102-111, 2015. Disponível em: https://journals.openedition.org/revestudsoc/9313. Acesso em: 20 mar. 2020.

ACEVEDO, Á. El movimiento estudiantil entre dos épocas: cultura política, roles y consumos. Años sesenta. Historia de la Educación Colombiana, Nariño, n. 6-7, p. 161176, 2004. Disponível em: https://dialnet.unirioja.es/servlet/articulo?codigo=5019020. Acesso em: 20 mar. 2020.

ACEVEDO, Á. Modernización universitaria y protesta estudiantil en Colombia: el caso de la Universidad Industrial de Santander (1953-1977). Anuario de Historia Regional y de las Fronteras, Santander, v. 17, n. 2, p. 371-399, 2012. Disponível em: https://revistas. uis.edu.co/index.php/anuariohistoria/article/view/3073. Acesso em: 20 mar. 2020.

ACEVEDO, Á.; SAMACÁ, G. A. Revolución y cultura en América Latina: el movimiento estudiantil como objeto de estudio en la historiografía colombiana y continental. Memoria y Sociedad, Bogotá, n. 15, p. 104-119, 2011. Disponível em: https://revistas.javeriana.edu.co/index.php/memoysociedad/article/view/8286. Acesso em: 20 mar. 2020.

ACEVEDO, Á.; ROMERO, F. P. Orígenes del trotskismo en Colombia: de los colectivos socialistas revolucionarios al Bloque Socialista (1971-1977). Historia Caribe, Barranquilla, v. 14, n. 34, p. 123-149, 2019. Disponível em: http://investigaciones. uniatlantico.edu.co/revistas/index.php/Historia_Caribe/article/view/2110. Acesso em: 20 mar. 2020.

ALLIER, A. E. Presentes-pasados del 68 mexicano. Una historización de las memorias públicas del movimiento estudiantil, 1968-2007. Revista Mexicana de Sociología, Coyoacán, n. 2, p. 287-317, 2009. Disponível em: http://www.scielo.org.mx/scielo. php?script=sci_arttext\&pid=S0188-25032009000200003. Acesso em: 20 mar. 2020.

BARROS, J. D’A. Teoria da História. Petrópolis: Vozes, 2012.

BRAGHINI, K. Z.; CAMESKI, A. S. "Estudantes democráticos": a atuação do movimento estudantil de "direita" nos anos 1960. Educação e Sociedade, Campinas, v. 36, n. 133, p. 945-962, 2015. Disponível em: http://www.scielo.br/scielo.php?pid=S010173302015000400945\&script=sci_abstract\&tlng=pt. Acesso em: 20 mar. 2020.

BURKE, P. A Escola dos Annales, 1929-1989. São Paulo: Unesp, 2003.

CHIZZOTTI, A. A pesquisa qualitativa em Ciências Humanas e Sociais: evolução e desafios. Revista Portuguesa de Educação, Braga, v. 16, n. 2, p. 221-236, 2003. Disponível em: http:/www.grupodec.net.br/wp-content/uploads/2015/10/pesquisa_qualitativa_em_ciencias_ sociais_e_humanas_-_evolucoes_e_desafios_1_.pdf. Acesso em: 20 mar. 2020. 
CRUZ, E. La izquierda se toma la universidad: la protesta universitaria en Colombia durante los años sesenta. Izquierdas, Santiago, n. 29, p. 205-232, 2016. Disponível em: https://scielo.conicyt.cl/pdf/izquierdas/n29/art08.pdf. Acesso em: 20 mar. 2020.

DELGADO, K. S. El Partido Comunista Mexicano y el movimiento estudiantil de 1968: enfrentamiento, aportación e impacto. 2013. 243 p. Tesis (Doctorado en Historia) Programa de Postgrado en Historia, Universidad Autónoma de Querétaro, Querétaro, 2013.

DONOSO, A. El movimiento estudiantil mexicano de 1968 en clave latinoamericana: aproximación a las nociones de educación y transformación social. Historia Crítica, Bogotá, n. 63, p. 137-157, 2017. Disponível em: http://www.scielo.org.co/pdf/rhc/n63/0121-1617-rhc63-00137.pdf. Acesso em: 20 mar. 2020.

FUENTES, C. Em 68: Paris, Praga e México. Rio de Janeiro: Rocco, 2008.

HERNÁNDEZ, I. El programa mínimo de los estudiantes colombianos. Movimiento estudiantil universitario de 1971 por la universidad. Todo un país. Historia de la Educación Colombiana, Nariño, n. 10, p. 29-57, 2007. Disponível em: http://editorial.udenar.edu.co/revistas/rudecolombia/files/r10_29.pdf. Acesso em: 20 mar. 2020.

JIMÉNEZ, H. El 68 y sus rutas de interpretación: una crítica historiográfica. 2011. 240 p. Tesis (Maestría en Historiografía de México) - Programa de Postgrado en Historiografía de México, Universidad Autónoma Metropolitana Azcapotzalco, Ciudad de México, 2011.

MARINI, R. M. Los movimientos estudiantiles en América Latina, un marco de referencias. Ciencia Social, Concepción, p. 110-122, 1970. Disponível em: http://www.scielo.org.mx/pdf/soc/v23n68/v23n68a7.pdf. Acesso em: 20 mar. 2020.

MORAES, J. Q. A mobilização democrática e o desencadeamento da luta armada no Brasil em 1968: notas historiográficas e observações críticas. Tempo Social, São Paulo, v. $1, \quad$ n. 2 , p. 135-158, 1989. Disponível em: http://www.scielo.br/scielo.php?script=sci_arttext\&pid=S0103-20701989000200135.

Acesso em: 20 mar. 2020.

MORAES FREIRE, S. Movimento estudantil no Brasil: lutas passadas, desafios presentes. Revista Historia de la Educación Latinoamericana, Boyacá, v. 11, p. 131-146, 2008. Disponível em: https://biblat.unam.mx/hevila/Revistahistoriadelaeducacion latinoamericana/2008/vol11/6.pdf. Acesso em: 20 mar. 2020.

PITTS, B. "O sangue da mocidade está correndo": a classe política e seus filhos enfrentam os militares em 1968. Revista Brasileira de História, São Paulo, v. 34, n. 67, p. 39-65, 2014. Disponível em: http://www.scielo.br/pdf/rbh/v34n67/a03v34n67.pdf. Acesso em: 20 mar. 2020.

RAMOS, M. P.; MONSMA, K. Apresentação. Sociologias, Porto Alegre, n. 31, p. 14-18, 2012. Disponível em: http://www.scielo.br/pdf/soc/v14n31/02.pdf. Acesso em: 20 mar. 2020. 
REIS FILHO, D. A. 1968: o curto ano de todos os desejos. Tempo Social, São Paulo, v. 10, n. 2, p. 25-35, 1998. Disponível em: http://www.scielo.br/pdf/ts/v10n2/v10n2a03.pdf. Acesso em: 20 mar. 2020.

SOARES, M. L. A.; PETARNELLA, L. 1968, o ano que ainda faz pensar: intelectuais indagam sobre a irrupção dos jovens na sociedade industrial. Avaliação, Campinas, v. 14, n. 2, p. 337-350, 2009. Disponível em: http://www.scielo.br/pdf/aval/v14n2/a06v14n2.pdf. Acesso em: 20 mar. 2020.

SOSA, Y. H. La protesta estudiantil en la Universidad del Valle entre 1968-1971 y 20072011. Una lectura comparada. Forum Revista, Medellín, v. 13, p. 33-74, 2018. Disponível em: https://revistas.unal.edu.co/index.php/forum/article/view/69625/66868. Acesso em: 20 mar. 2020.

VASCONCELOS, J. G.; FIALHO, L.; LOPES, T. M. Educação e liberdade em Rousseau. Educação \& Formação, Fortaleza, v. 3, n. 8, p. 210-223, 2018. Disponível em: https://revistas.uece.br/index.php/redufor/article/view/278/206. Acesso em: 20 mar. 2020.

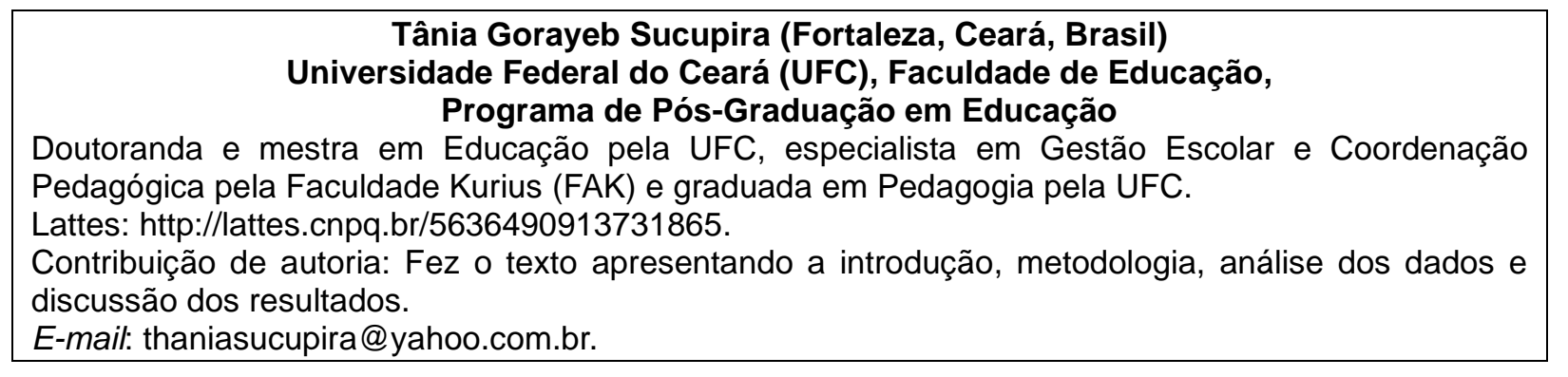

Francisco Javier García Delgado (Huelva, Andaluzia, Espanha)

Universidade de Huelva (UH), Departamento de História, Instituto de Desenvolvimento Local Profesor titular de História II y Geografia da UH.

Contribuição de autoria: Coletou os dados e realizou a metodologia, análise dos dados e revisão final. E-mail: fcogarci.uhu@gmail.com.

Editora responsável: Lia Machado Fiuza Fialho Pareceristas ad hoc: Hugo Heredia Ponce e Norberto Dallabrida

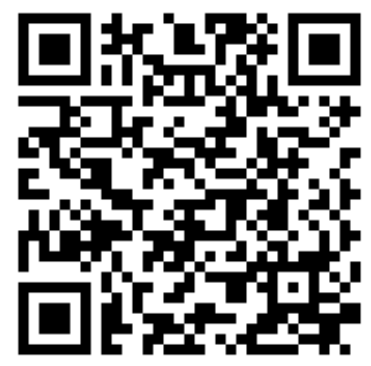

Recebido em 03 de fevereiro de 2020.

Aceito em 07 de março de 2020.

Educação \& Formação, Fortaleza, v. 5, n. 14, p. 216-239, maio/ago. 2020

DOI: https://doi.org/10.25053/redufor.v5i14mai/ago.2750

http://seer.uece.br/redufor 